\title{
Dark-field illumination in conjunction with confocal Raman spectroscopy for real-time noninvasive aqueous humor investigation
}

Citation for published version (APA):

Zhang, S., Erckens, R. J., Jongsma, F. H. M., De Brabander, J., Webers, C. A. B., \& Berendschot, T. T. J. M. (2020). Dark-field illumination in conjunction with confocal Raman spectroscopy for real-time noninvasive aqueous humor investigation. Optical Engineering, 59(9), [092002]. https://doi.org/10.1117/1.OE.59.9.092002

Document status and date:

Published: 01/09/2020

DOI:

10.1117/1.OE.59.9.092002

Document Version:

Publisher's PDF, also known as Version of record

Document license:

Taverne

Please check the document version of this publication:

- A submitted manuscript is the version of the article upon submission and before peer-review. There can be important differences between the submitted version and the official published version of record.

People interested in the research are advised to contact the author for the final version of the publication, or visit the DOI to the publisher's website.

- The final author version and the galley proof are versions of the publication after peer review.

- The final published version features the final layout of the paper including the volume, issue and page numbers.

Link to publication

\footnotetext{
General rights rights.

- You may freely distribute the URL identifying the publication in the public portal. please follow below link for the End User Agreement:

www.umlib.nl/taverne-license

Take down policy

If you believe that this document breaches copyright please contact us at:

repository@maastrichtuniversity.nl

providing details and we will investigate your claim.
}

Copyright and moral rights for the publications made accessible in the public portal are retained by the authors and/or other copyright owners and it is a condition of accessing publications that users recognise and abide by the legal requirements associated with these

- Users may download and print one copy of any publication from the public portal for the purpose of private study or research.

- You may not further distribute the material or use it for any profit-making activity or commercial gain

If the publication is distributed under the terms of Article $25 \mathrm{fa}$ of the Dutch Copyright Act, indicated by the "Taverne" license above, 


\title{
Dark-field illumination in conjunction with confocal Raman spectroscopy for real-time noninvasive aqueous humor investigation
}

\author{
Shuo Zhang, Roel J. Erckens, Frans H. M. Jongsma, John De Brabander, \\ Carroll A. B. Webers, and Tos T. J. M. Berendschot* \\ University Eye Clinic Maastricht, Maastricht, The Netherlands
}

\begin{abstract}
To obtain a real-time noninvasive analysis of the content of the aqueous humor (AH) in the eye, a confocal dark-field ophthalmic probe was designed and optimized by ray-tracing software. The confocal technique allows Raman spectrometric sampling of the AH with suppressing signals from the surrounding tissues. Dark-field illumination prevents the excitation light to reach the vulnerable retinal tissue directly. In order to evaluate the optical performance and safety of this method, a functional prototyped eye contact probe has been designed and tested on ex vivo rabbit eyes. (c) 2020 Society of Photo-Optical Instrumentation Engineers (SPIE) [DOI: 10.1117/1.OE.59.9.092002]
\end{abstract}

Keywords: Raman spectroscopy; eye; aqueous humor; confocal microscopy; dark-field illumination.

Paper 191724SS received Dec. 13, 2019; accepted for publication Mar. 27, 2020; published online May 4, 2020.

\section{Introduction}

The anterior chamber (AC) (Fig. 1) contains an ocular fluid called aqueous humor (AH), the functions of which are maintaining eye pressure and providing nutrition to the cornea and lens. If these proteins, nucleotides, and metabolites in the AH could be detected, they could be helpful in understanding ocular diseases. ${ }^{1-3}$ Glucose levels in AH correlate with those in blood plasma and may be used as an indicator of diabetes complications in the eye. ${ }^{4-6}$ Inflammatory cytokine profiles in the $\mathrm{AH}$ could reveal associations with glaucoma, the leading irreversible cause of blindness. ${ }^{7}$ Further, recently it was shown that three ocular proteins in the AH can be used as a diagnostic aid for several retinal disease diagnoses. ${ }^{8}$ The current standard in clinical practice to analyze AH is invasive biopsy. However, this approach has several drawbacks: first, breaking the integrity of the eye raises the risk of inflammation. Second, it is a burden to the patients, which impairs its frequent use. Third, the procedure requires multiple devices and a clinical environment. Fourth, it also bears the risk of changing the composition of the AH during the process.

To understand the mechanism of eye diseases, it is preferable to investigate the physiological and pathological changes in real time of the eye with noninvasive methods. Since the eye is transparent in the electromagnetic spectrum of 350 to $2000 \mathrm{~nm}$, several optical diagnostic techniques have been developed for anterior eye section examinations, such as biomicroscopy (slit lamp) and optical coherence tomography (OCT). ${ }^{9}$ However, these morphological examinations are lacking the ability of revealing the biochemical information of ocular tissues. Raman spectroscopy can do this in a noninvasive way. ${ }^{10}$ The Raman effect is associated with inelastic scattering from vibrations or rotations of chemical bonds, and therefore the spectra have a specific fingerprint for each biomedical molecule due to their unique atomic composition and structure. As such, Raman spectroscopy is capable of identifying targeted tissues both qualitatively and quantitatively and is therefore widely used for molecular identification in biomedical and preclinical applications. ${ }^{2,11-14}$ To evaluate the feasibility of our Raman spectroscopy system for ocular research, the first Raman spectroscopy experiments of our research group to measure

*Address all correspondence to Tos T. J. M. Berendschot, E-mail: t.berendschot@maastrichtuniversity.nl 


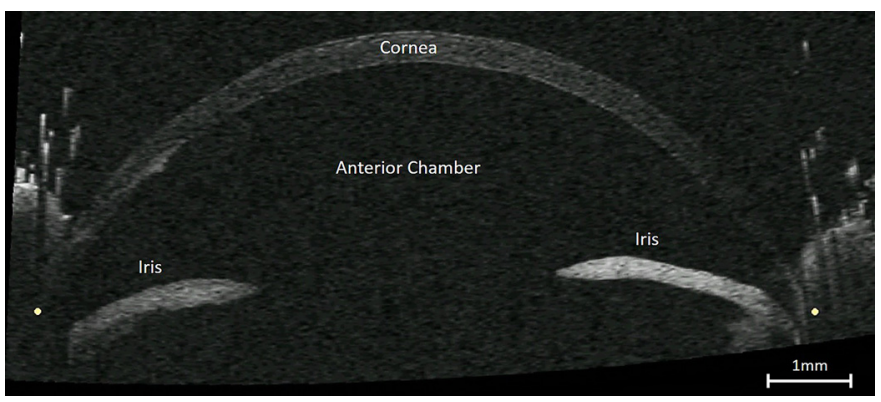

Fig. 1 OCT image of anterior segment of a rabbit eye, acquired with a Heidelberg Engineering BD900 SL-OCT.

a rabbit eye were performed in 1990s at the UTMB in Galveston, Texas. ${ }^{15}$ With a setup using an 514.5-nm wavelength argon ion laser as excitation source and a liquid nitrogen-cooled spectrometer, good isolated Raman spectra of the $\mathrm{AH}$ of an ex vivo rabbit eye were obtained as a proof of principle experiments. ${ }^{16}$

To obtain a high signal-to-noise ratio in Raman spectroscopy, a laser is indispensable as an excitation source. However, radiation limitations for light damage of retinal tissue are strict when employing laser light. ${ }^{16,17}$ There are two kinds of light hazard in the eye. Wavelengths below $550 \mathrm{~nm}$ might cause photochemical light damage on the retinal tissue. ${ }^{17}$ Here, exposure time is limited due to its cumulative effect on living tissue. Longer wavelengths do not induce photochemical light damage and have the benefit of suppressing the disturbing background fluorescence. However, with longer wavelengths the danger of thermal damage increases while Raman responses decrease. For this reason, we chose excitation wavelengths at the end of the visual spectrum - that is patient friendly — of 671 and $785 \mathrm{~nm}$ at relative low intensities of 10 to $25 \mathrm{~mW}$ with prolonged exposure times of 60 to $90 \mathrm{~s}$. Note that even this power excitation is unsafe when direct laser radiation reaches the retinal tissue. To prevent the latter and guarantee an eye safe usage, we designed and constructed a circular symmetric Raman eye probe for clinical use with the principle of "dark-field" illumination in which only scattered light can reach the patients retina. The optical performance of this probe will be presented in this paper using simulation diagrams. In addition, we will show results of ex vivo test in rabbit eyes using a prototype of the probe.

\section{Design}

To evaluate its optical principles, the basic structure of the probe was first designed and developed by ray-tracing software Zemax (version 16.5 Sp3, Zemax LLC, Kirkland, Washington). After performance optimization and validation of the design, the three-dimensional (3-D) model for manufacturing was generated by Autodesk inventor (professional version 2016, Autodesk Corp., San Rafael, California). In the end, the 3-D model was imported into Zemax again for final check (such as tolerance influence) before fabricating the prototype.

The spectrometer provides an excitation beam with a waist of about $18 \mu \mathrm{m}$. For simplicity, we assumed a point light source in ray-tracing for the optical setup. To optimize our dark-field design with Zemax, a Liou-Brennan eye model was used. ${ }^{18}$ All ray-tracings were done at $785 \mathrm{~nm}$.

\subsection{Optical Design}

To prevent light damage on retinal tissue, direct excitation of the posterior part of the eye should be avoided. We have opted for the approach to apply dark-field illumination principle for patients, with the incident laser light passing through the periphery of the cornea and focusing on the AC. This way it ends up in iris tissue instead of directly reaching the retina and only the scattered light can reach the posterior parts of the eye through the crystalline lens. It offers an 
integration length of about $0.5 \mathrm{~mm}$ (calculated for a $25-\mu \mathrm{m}$ pinhole) perpendicular to the optical axis of the eye and the numerical aperture (NA) of the probe could be designed to match that of the Raman spectrometer $(\mathrm{NA}=0.05)$.

The probe was designed and developed based on a former patent [Fig. 2(a)]. ${ }^{19}$ Unfortunately, alignment of this model proved to be so difficult, that no reproducible results could be obtained. In particular, the distance between the focusing lens and the probe proved to be critical. In the redesigned probe, a central mirror focuses the collimated incoming light that is further guided by two conical mirrors into the eye. This design eliminates the degree of freedom for the distance between separated focusing lens and the probe formerly patented [region 1, Fig. 2(a)]. A collimated beam is sufficient as an incident beam for the redesigned probe [region 1, Fig. 2(b)]. Applying a mirror-only system, chromatic aberration induced by the focusing lenses is also no longer present.

Figure 2(b) shows a schematic representation of the newly designed probe. ${ }^{20}$ It is formed by three mirrors $(2,3$, and 4$)$, where surface 2 is an aspherical concave aluminum mirror to provide focusing power. The rotationally symmetric aspheric concave mirror can be described as

(a)
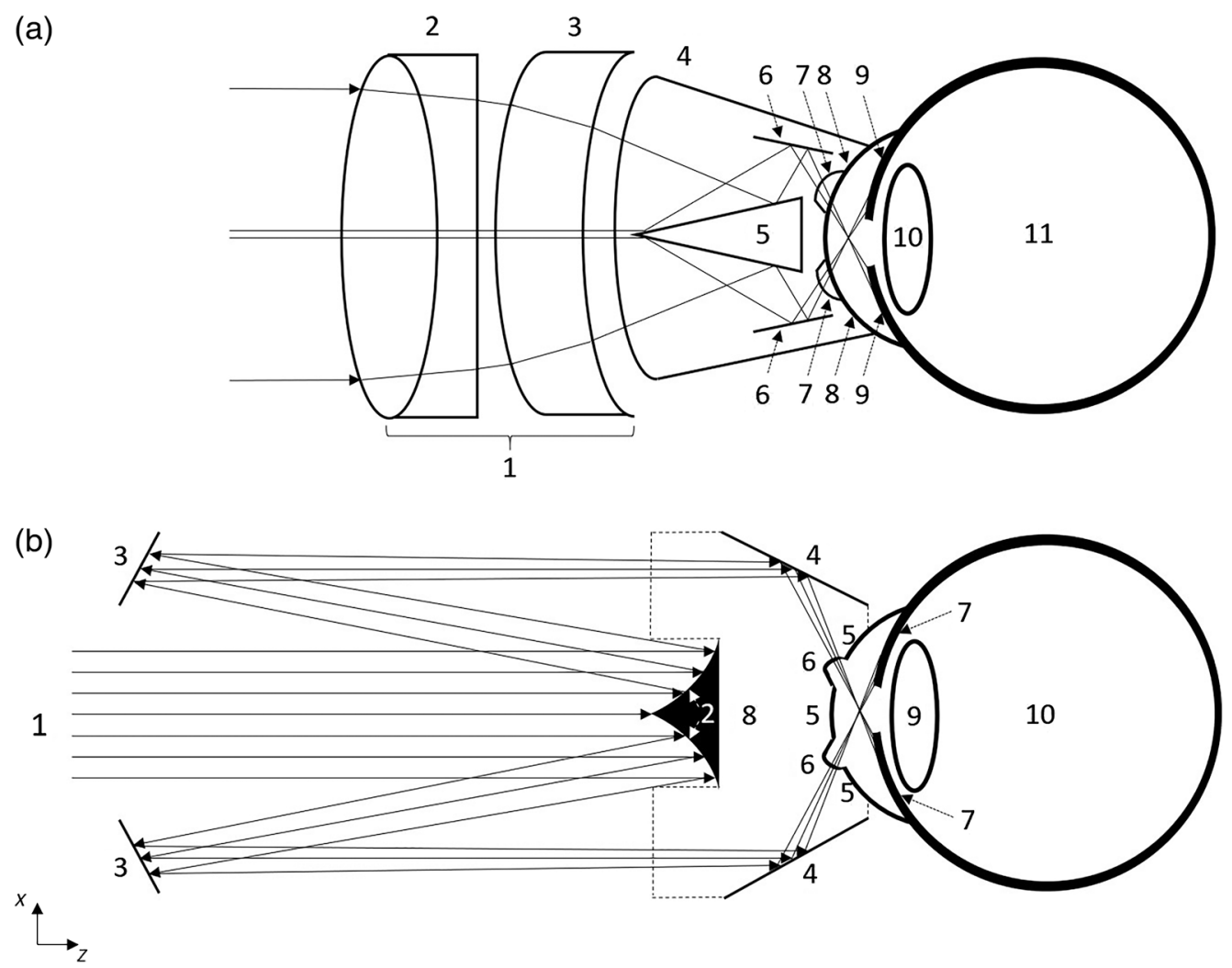

Fig. 2 Design of the ophthalmic probe. (a) In former patented design, (1) a focusing lens with (2) an entry surface and (3) an exit surface is used to provide focusing power and (4) a spherical surface adapted to the converging beam without adding further focusing power is also used to acting as a contact probe guides the light into (11) the eye. (5) An internal conical mirror reflects the light to a further (6) conical mirror which further directs the light into the anterior eye chamber through (7) an interface and (8) cornea surface. The excitation light will end on (9) the iris, only scattering light reaches the posterior part of the eye through (10) the crystalline lens. (b) In the newly designed probe, (1) the collimated incident light directly reached (2) an aspherical concave mirror which provides focusing power of the probe. The reflected light is guided by (3) a rotationally symmetric flat mirror to feed into the main body of (8) the probe and direct to (10) the eye by (4) surface through (6) an interface on (7) the corneal interface surface. The excitation light will end on (7) the iris tissue, only scattering could reach the posterior part of the eye through (9) the crystalline lens. 


$$
z=\frac{c r^{2}}{1+\sqrt{1-(1+k) c^{2} r^{2}}}+\beta_{1} r^{1}+\beta_{2} r^{2}+\cdots
$$

Here $c$ is the curvature (the reciprocal of the radius) and $r$ is the radial coordinate. To have a focusing effect, it implies that a parabola curve is needed for the two-dimensional cross-section curvature. Hence, the conic constant $k=-1$ and the equation can be written as

$$
z=\beta_{1} r^{1}+\left(\frac{1}{2} c+\beta_{2}\right) \times r^{2}
$$

where $\beta_{1}$ and $\beta_{2}$ were both optimized and obtained by Zemax simulations, respectively. Surface 3 is a rotationally symmetric flat aluminum mirror that guides the laser beam to surface 4 properly. The mirror is tilted toward the curved mirror with $6.7 \mathrm{deg}$ and $7.5 \mathrm{~mm}$ long measured in cross section. The distance between surface 2 and surface 3 is also optimized by Zemax to ensure a focus in the central part of the AC. Surface 4 is an interface of poly(methyl methacrylate) (PMMA) and air, which functions as a mirror by total internal reflection.

The eye fitting part was carefully designed to fit the cornea. As shown in Fig. 2(b), the direction of the light beam guided by mirror 3 and surface 4 was designed such that it reaches the eye fitting surface perpendicularly, this to avoid extra refraction and minimize power loss. The diameter of the eye fitting component was $26.3 \mathrm{~mm}$ for the outer diameter of the probe and $15 \mathrm{~mm}$ for the eye fitting part. Its length was $7.5 \mathrm{~mm}$ in total. Surface 4 was tilted $51 \mathrm{deg}$ from the horizontal surface to obtain total internal reflection in the PMMA body of the design. Through a special designed interfacial surface [6 in Fig. 2(b)] with a radius of $8 \mathrm{~mm}$ and a chord length of $0.6 \mathrm{~mm}$, astigmatism caused by the corneal surface could be avoided. The laser will focus on the AC 1.2$\mathrm{mm}$ deep under the top of corneal surface. Hereafter, the light will be absorbed in the region between cornea and iris. We assumed an 8-mm pupil, the edge of which also being the edge of the incident beam as shown in surface 7 in Fig. 2(b). Finally, the eye fitting surface was designed with a radius of $7.9 \mathrm{~mm}$ to match the curvature of the cornea. For patient comfort, all corners are rounded with varies of radius, respectively.

\subsection{Prototype Manufacture}

Based on the optimization by ray-tracing, the optical design as explained above was used to produce a prototype of the probe (Fig. 3). The central focusing mirror [surface 2 in Fig. 2(b)] and the conical-shaped mirror [surface 3 in Fig. 2(b)] were made by polished aluminum to obtain a high reflectivity and quartz coating to prevent oxidation. The PMMA body of the probe with a refractive index of 1.487 at $671 \mathrm{~nm}$ and 1.485 at $785 \mathrm{~nm}^{21}$ ensures total internal reflection at surface 4 and transmission at interface 6 . All parts of the probe were produced using a highprecision lathe.

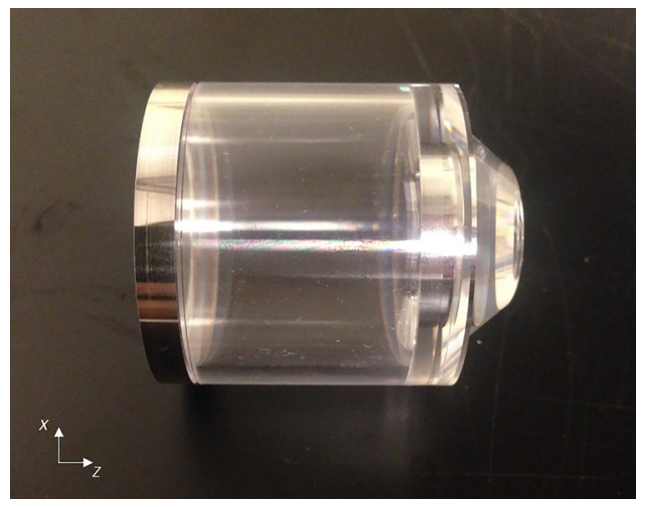

Fig. 3 Assembled prototype probe. 


\section{Measurement}

\subsection{Confocal Raman Spectroscopy}

To bring Raman spectroscopy into the clinic, a compact and easy to transport spectrometer was used. Figure 4 shows the schematic representation of the confocal Raman spectroscopy (CRS) setup. It consists of a Raman spectrometer with two integrated excitation sources, one for the fingerprint region and one for the longer wavelength shift, a dark-field eye probe, and a sample stage. The confocal setup with $25-\mu \mathrm{m}$ pinhole minimizes possible contributions of out of focus signals that are generated in tissues along the pathway. ${ }^{22}$

As excitation sources a $15-\mathrm{mW}$ diode laser with a wavelength of $785 \mathrm{~nm}$ (Innovative Photonic Solutions SM $785 \mathrm{~nm}$, Monmouth Junction) and a 20-mW diode laser with a wavelength of $671 \mathrm{~nm}$ (Laser Quantum Ignis 671 and SMD 6000, Konstanz, Germany) were utilized. A high-performance Raman spectrometer (Module Model 2500, River Diagnostics ${ }^{\circledR}$, Rotterdam, The Netherlands) was employed with a charge-coupled device camera to record the Raman spectra at a working temperature of $-65^{\circ} \mathrm{C}$. The module receives the laser excitation light through two single-mode diamond optical fibers. A $25-\mu \mathrm{m}$ pinhole was placed in the spectrometer to allow the laser beams - that have a waist of about $18 \mu \mathrm{m}$-pass into the measurement area. An 80-mm focal length doublet lens was placed after the spectrometer aperture to change the diverging beam $(\mathrm{NA}=0.05)$ into an 8 -mm-diameter parallel beam. Alignment of the $80-\mathrm{mm}$ collimating lens was achieved with a shearing interferometer to obtain a perfect parallel excitation beam that is coupled into the eye probe.

The eye probe was mounted in a gimbal mirror mounts (BHAN-50M, OptoSigma ${ }^{\circledR}$, Les Ulis, France), with fine adjustment in horizontal and vertical directions. Maximum adjustment range is $\pm 4 \mathrm{deg}$, resolution of rotation is $0.31 \mathrm{deg}$ and $0.48 \mathrm{deg}$ in $x$ and $y$ axes separately. Alignment in the sample was performed by translation and rotation adjustments of the gimbal until the maximum signal appeared.

All Raman spectra were processed by a self-developed MATLAB program (Version 2017b, The Mathworks Inc., Natick). ${ }^{23}$

\subsection{Sample Preparation}

Enucleated eyes from sacrificed New Zealand white rabbits were stored in $-80^{\circ} \mathrm{C}$ freezers before use. The eyes were thawed at room temperature then submerged in phosphate-buffered saline

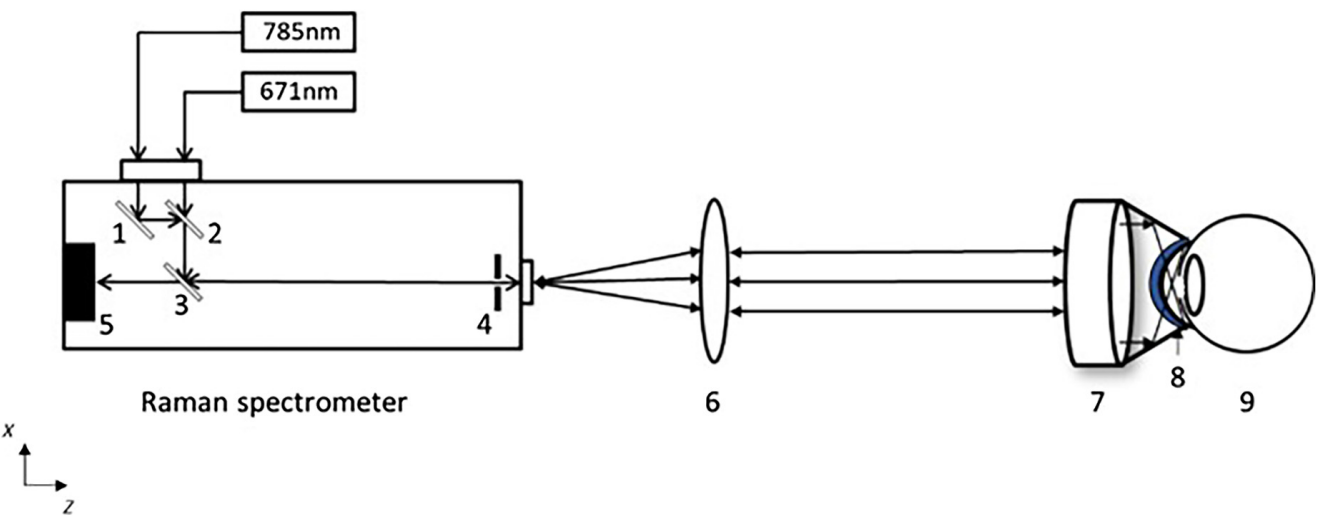

Fig. 4 Schematic of the optical setup. The circle symmetric probe, the diode lasers (671 and $785 \mathrm{~nm}$ ) are coupled on one optical axis by a (1) mirror and (2) and (3) dichroic mirror within the spectrometer. The excitation light leaves the spectrometer through (4) an integrated $25-\mu \mathrm{m}$ pinhole. (6) An $f=80-\mathrm{mm}$ achromat collimates the excitation beam before it enters (7) the gimbalmounted probe. (9) The eye is optically coupled to the probe with (8) an ophthalmic gel. The backscattered Raman radiation that fits into the $N A=0.05$ optical system is transported back into the spectrometer and recorded by (5) a CCD. Due to this coincidence setup, the spectrometer facilitates a confocal isolation of the $\mathrm{AH}$ from the about $100 \times$ stronger Raman signal from the corneal tissue. 
(pH 7.4) to prepare for use. $150-\mu 1$ volume $\mathrm{AH}$ was removed from the rabbit eye by a syringe with $30 \mathrm{G}$ needle. Subsequentially, the same volume of phenylephrine $\mathrm{HCl} 10 \%$ (Bausch \& Lomb UK Limited, Surrey, United Kingdom) was injected by another 30G needle syringe into the AC. All animal sample procedures were conducted under the Guidelines of the Central Laboratory Animal Facility of Maastricht University and complied with the ARVO Statement for the Use of Animals in Ophthalmic and Visual Research. All protocols were approved by the Central Committee for Animal research and were in accordance with the European Guidelines (2010/63/EU).

For the prototype probe as shown in Fig. 3, topically applied Methoce ${ }^{\circledR} 2 \%($ OmniVision, Santa Clara, California) was used as an ophthalmic gel. It functions both to moister the cornea and to remove air between the probe and the eye. The gel has a refractive index of 1.469, which also bridges the refraction index difference of the probe (1.487) and cornea (1.376).

\section{Results and Discussions}

\subsection{Ray-Trace Simulation}

In Fig. 5(a), the spot diagram shows that the root-mean-square (RMS) radius of the excitation light $(785 \mathrm{~nm}$ ) focus in the $\mathrm{AC}$ is $6.684 \mu \mathrm{m}$ and the geometric (GEO) radius is $18.577 \mu \mathrm{m}$. The RMS radius gives a rough idea of the spread of the focus spot while the GEO radius indicates the distance of farthest illuminated boundary from the center. Due to the small aperture and the long wavelength, this is an about diffraction limited spot. Figure 5(b) shows the cumulative normalized energy as function of the encircled radius. When properly aligned, nearly all energy was collected within a $12-\mu \mathrm{m}$ radius (triangle-labeled line). In case of a severe $(3.5 \mathrm{~mm}$ ) lateral misalignment with the probe, the ray-traced focus showed a scattered power distribution in a broad area outside the focal area (dots labeled line). However, with already a slight rotation misalignment of $0.3 \mathrm{deg}$ in one direction, no energy at all is collected within a $12-\mu$ m radius (square-labeled line). A recognizable signal can only be obtained with a $100-\mu \mathrm{m}$ radius, implying that the widths of the pinhole of the spectrometer need to be $200 \mu \mathrm{m}$ to collect a considerable amount of the Raman backscattered light. However, a 200- $\mu \mathrm{m}$ pinhole destroys the confocal effect necessary to limit the integration length in the $\mathrm{AH}$.

The simulation indicates the extreme sensitivity for rotation misalignment. Under such a misalignment, the focus of the excitation light is displaced and disrupted into scattered elements. Hence, the collected Raman signal obtained from such an element will be strongly decreased and

(a)

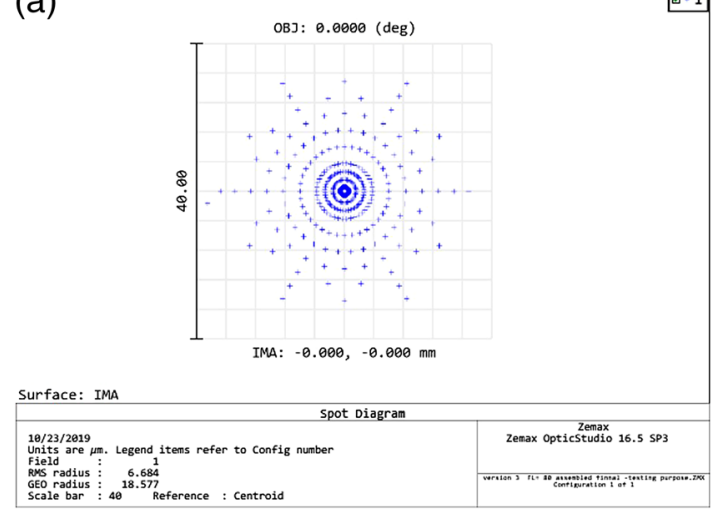

(b)

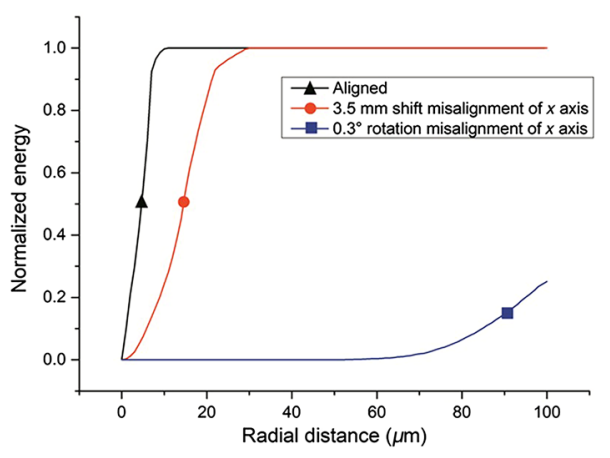

Fig. 5 Simulation result of the newly designed probe. In Fig. 5(a), the spot diagram shows that the RMS radius of the focus is $6.684 \mu \mathrm{m}$ and the GEO radius is $18.577 \mu \mathrm{m}$. In Fig. $5(\mathrm{~b})$, the encircled radius of cumulative normalized energy diagram shows that aligned probe (triangle-labeled line) could collect nearly all energy within a $12-\mu \mathrm{m}$ radius (square-labeled line). A recognizable signal can only be obtained with a $100-\mu \mathrm{m}$ radius; $3.5-\mathrm{mm}$ lateral misalignment (dots labeled line) could collect nearly all energy within a $30-\mu \mathrm{m}$ radius; a rotation misalignment of 0.3 deg leads to a recognizable signal with around $100 \mu \mathrm{m}$ radius. 

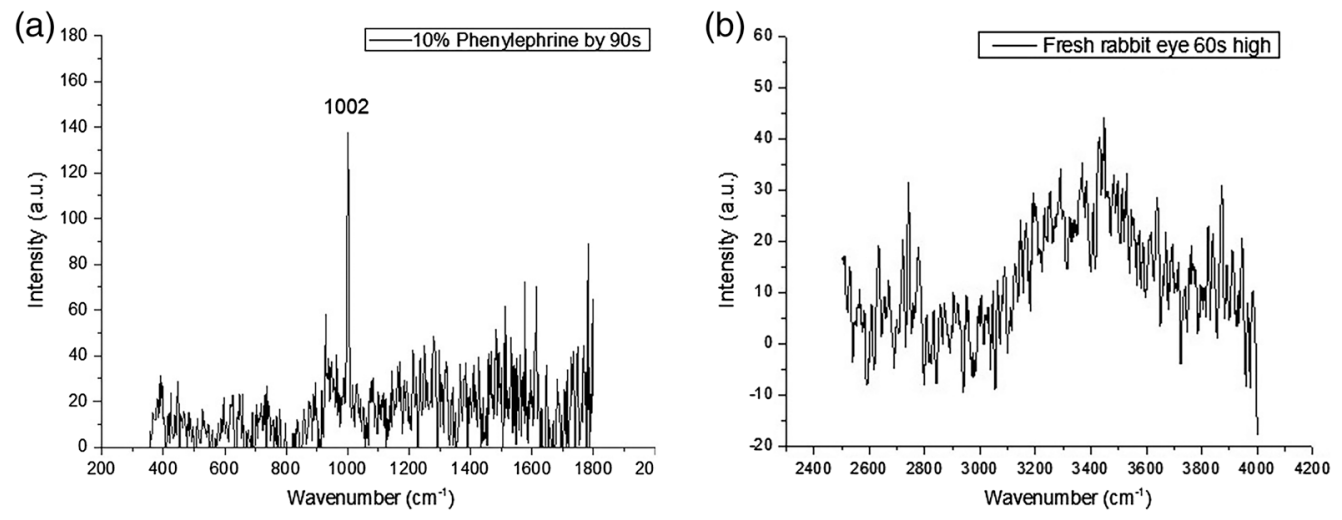

Fig. 6 Raman spectrum obtained by the prototype probe with (a) 10\% phenylephrine in $90-\mathrm{s}$ integration time and (b) water $\mathrm{OH}$ bending mode in 60-s integration time.

will not be a guidance to proper focusing. The decreased maximum intensity after the focus and the disrupted intensity distribution will minimize the light damage of the tissue accordingly.

\subsection{Raman Spectrum}

The design of prototyped probe for measuring the Raman spectrum of the AH in a "dark-field" modality was tested on ex vivo rabbit eyes. To avoid the 100 times stronger signals of the surrounding tissues, a confocal setup was applied using a spectrometer of which the excitation light as well as the Raman signal was passing the same $25-\mu \mathrm{m}$ pinhole. In Fig. 6(a), a peak at the wavenumber of $1002 \mathrm{~cm}^{-1}$ is observed with an exposure time of $90 \mathrm{~s}$ from the $\mathrm{AH}$ of a rabbit eye with phenylephrine injection. The peak position is the same as the ocular drug phenylephrine which formerly reported by Elshout et al. ${ }^{24}$ In Fig. 6(b), the AH showed a spectral response from the $\mathrm{OH}$ bending mode of water at an exposure time of $60 \mathrm{~s}$.

Although the prototyped probe showed a recognizable Raman signal, it was by far not the signal that could be easily obtained due to the alignment difficulties which is also revealed by the simulation results. More effort was needed to achieve this alignment, which is an unsurmountable obstacle for ophthalmologists during clinical practice.

\subsection{Data Processing}

$\mathrm{AH}$ contains variant compounds including inorganic ions and organic anion, carbohydrates, glutathione and urea, proteins, growth-modulatory factors, oxygen, and carbon dioxide. ${ }^{1}$ Not all of them are Raman active since the Raman scattering mainly related to the vibrational, rotational, and other low-frequency modes of intramolecular bonds. These compounds in $\mathrm{AH}$ are dynamically interchanging with many tissues inside the eye, but $\mathrm{AH}$ is in a closure environment with stable exchange rate of 2 to $3 \mu \mathrm{l} / \mathrm{min}$ in a health human eyes ${ }^{1}$ and exchange rate of 2.6 to $3.6 \mu \mathrm{l} / \mathrm{min}$ in rabbit eyes, ${ }^{25}$ which can be considered as static comparing with the Raman measurement time. In a multiple chemical mixture environment such as $\mathrm{AH}$, substance identification only by single peak might lead to a biased conclusion because some composition might share some chemical bonds in common. However, there is not a well-accepted data processing procedure available yet. ${ }^{26}$ In a previous study, we proposed and validated a MATLAB program for data processing of Raman detection of ocular drug topically delivered to the animal eyes in vitro and in vivo. ${ }^{23}$ It demonstrated that with proper data processing techniques, Raman spectroscopy could be used in ocular tissue investigation with an ophthalmic probe.

\section{Conclusion}

In this study, simulation analysis and in vitro tests indicated that the dark-field probe as prototyped is suitable for applying on human eyes. Recognizable Raman signals were acquired from the ex vivo rabbit eyes as proof of principle. This design demonstrated the potential for real-time, 
noninvasive Raman AH measurements. However, difficulties to achieve alignment hinder its clinical application and further improvement is needed. Development of a probe with a less critical rotational alignment and of which the signal during the alignment guides the operator to a proper alignment will be the next step in our research.

\section{Acknowledgments}

We would like to thank Sumipro B.V. for their advice while manufacturing the prototype and Theresa Kocanda for her help while evaluating the performance of probe prototype. We also would like to thank Christian J.F. Bertens for his help while obtaining the OCT image of the rabbit eye in Fig. 1. Shuo Zhang acknowledges the China Scholarship Council for the support by

State Scholarship Fund No. 201309110103. The authors declare that there are no conflicts of interest to disclose.

\section{References}

1. L. M. Levine, "Basic and clinical science course, section 2: fundamentals and principles of ophthalmology," in Basic and Clinical Science Course, L. M. Levine et al., Eds., p. 430, American Academy of Ophthalmology, San Francisco, California (2018-2019).

2. S. H. Yun and S. J. J. Kwok, "Light in diagnosis, therapy and surgery," Nat. Biomed. Eng. 1(1), 0008 (2017).

3. R. J. Erckens et al., "Raman spectroscopy in ophthalmology: from experimental tool to applications in vivo," Lasers Med. Sci. 16(4), 236-252 (2001).

4. S. Pohjola, "The glucose content of the aqueous humour in man," Acta Ophthalmol. 44(Suppl. 88), 81 (1966).

5. M. Reim et al., "Steady state levels of glucose in the different layers of the cornea, aqueous humor, blood and tears in vivo," Ophthalmologica 154(1), 39-50 (1967).

6. C. C. Pelletier, J. L. Lambert, and M. Borchert, "Determination of glucose in human aqueous humor using Raman spectroscopy and designed-solution calibration," Appl. Spectrosc. 59(8), 1024-1031 (2005).

7. T. Kokubun et al., "Characteristic profiles of inflammatory cytokines in the aqueous humor of glaucomatous eyes," Ocul. Immunol. Inflamm. 26(8), 1177-1188 (2018).

8. J. J. Kuiper et al., "An ocular protein triad can classify four complex retinal diseases," Sci. Rep. 7, 41595 (2017).

9. M. Kaschke, K.-H. Donnerhacke, and M. S. Rill, Optical Devices in Ophthalmology and Optometry: Technology, Design Principles and Clinical Applications, WILEY-VCHVerlag GmbH \& Co. KGaA, Germany (2014).

10. A. R. Boyd, G. A. Burke, and B. J. Meenan, "Monitoring cellular behaviour using Raman spectroscopy for tissue engineering and regenerative medicine applications," J. Mater. Sci. Mater. Med. 21(8), 2317-2324 (2010).

11. P. Chen et al., "Bio-Raman spectroscopy: a potential clinical analytical method assisting in disease diagnosis," Anal. Methods 3(6), 1257 (2011).

12. I. Pence and A. Mahadevan-Jansen, "Clinical instrumentation and applications of Raman spectroscopy," Chem. Soc. Rev. 45(7), 1958-1979 (2016).

13. K. J. I. Ember et al., "Raman spectroscopy and regenerative medicine: a review," npj Regener. Med. 2(1), 12 (2017).

14. Z. Movasaghi, S. Rehman, and I. U. Rehman, "Raman spectroscopy of biological tissues," Appl. Spectrosc. Rev. 42(5), 493-541 (2007).

15. F. H. Jongsma et al., "Confocal Raman spectroscopy system for noncontact scanning of ocular tissues: an in vitro study," Opt. Eng. 36(11), 3193-3199 (1997).

16. J. J. Vos and D. van Norren, "Retinal damage by optical radiation. An alternative to current, ACGIH-inspired guidelines," Clin. Exp. Optom. 88(4), 200-211 (2005).

17. P. International Commission on Non-Ionizing Radiation, "ICNIRP guidelines on limits of exposure to laser radiation of wavelengths between $180 \mathrm{~nm}$ and 1,000 $\mu \mathrm{m}$," Health Phys. 105(3), 271-295 (2013). 
18. H.-L. Liou and N. A. Brennan, "Anatomically accurate, finite model eye for optical modeling," J. Opt. Soc. Am. A 14(8), 1684-1695 (1997).

19. J. De Brabander and F. H. M. Jongsma, "Device and method for performing measurements of the chemical composition of the anterior eye," E. P. Office, Ed. (2008).

20. S. Zhang et al., "Device for performing measurements of the chemical composition of the anterior eye as well as an integrated optical unit for implementation therein," E. p. office, Ed., p. 29 (2018).

21. M. Szczurowski, "Refractive index and related constants-poly(methyl methacrylate) (PMMA, acrylic glass)," Refractiveindex.info (2013).

22. M. Minsky, "Memoir on inventing the confocal scanning microscope," Scanning 10(4), 128-138 (1988).

23. C. J. F. Bertens et al., "Confocal Raman spectroscopy: evaluation of a non-invasive technique for the detection of topically applied ketorolac tromethamine in vitro and in vivo," Int. J. Pharm. 570, 118641 (2019).

24. M. Elshout et al., "Detection of Raman spectra in ocular drugs for potential in vivo application of Raman spectroscopy," J. Ocul. Pharmacol. Ther. 27(5), 445-451 (2011).

25. S. D. Smith, "Measurement of the rate of aqueous humor flow," Yale J. Biol. Med. 64(1), 89-102 (1991).

26. H. J. Byrne et al., "Spectral pre and postprocessing for infrared and Raman spectroscopy of biological tissues and cells," Chem. Soc. Rev. 45(7), 1865-1878 (2016).

Shuo Zhang is a PhD candidate at the University Eye Clinic Maastricht. He received his BS degree in optics information and technology from Hebei University in 2008 and his MS degree in spectrometry from the Northwest Normal University in 2011. His current research interests include biomedical applications of Raman spectroscopy, spectroscopic data processing, and designing optoelectronic systems.

Roel J. Erckens is an ophthalmologist in the University Eye Clinic Maastricht. He received his $\mathrm{PhD}$ in the use of Raman spectroscopy in the eye from Maastricht University in 1995 . He is specialized in uveitis-related diseases diagnosis and treatment and Raman spectroscopy applications in ophthalmology.

Frans H. M. Jongsma received his $\mathrm{PhD}$ in shape measurements of the anterior eye from Maastricht University in 1998. After retiring, he still is involved in research on medical applications of Raman spectroscopy and other optical diagnostic technologies to study the anterior parts in the eye.

John De Brabander received his $\mathrm{PhD}$ in medical and technologic advancements in contact lenses from Maastricht University. He also, with a master on education sciences, acted as an educational coordinator for ophthalmology at Maastricht University. Although being retired, he still focuses on the development of measurement and imaging techniques for the diagnosis and treatment of the eye.

Carroll A. B. Webers is a full professor heading the University Eye Clinic Maastricht. In 1988, he received his $\mathrm{PhD}$ in laser trabeculoplasty from Radboud University Nijmegen. Ever since, his research has focused on the progression and prognostic factors of glaucoma, the medicinal and surgical treatment of glaucoma, and the consequences of this disease for the quality of life of patients.

Tos T. J. M. Berendschot received his PhD in applied physics from the University of Nijmegen in 1989. Currently, he is an associate professor at the University Eye Clinic Maastricht, studying the functional morphology of the human retina by noninvasive optical techniques. His recent work also involves epidemiological studies on the relation between nutrition, macular pigment, and eye diseases as well as the development of retinal image analysis using innovative braininspired mathematical algorithms and deep learning. 